\title{
La literatura infantil argentina, de los años ' 60 y ' 70 al presente: resistencia y continuidad literaria
}

\section{Argentinian Children's Literature, 60's and 70's - Present: Literary Resistance and Continuity}

\author{
Andrea Pac, Ana Cejas \\ apac@uarg.unpa.edu.ar, anitacejas2011@hotmail.com \\ Unidad Académica Río Gallegos - Universidad Nacional de la Patagonia Austral \\ Piloto Rivera s/n - Río Gallegos - Santa Cruz - Argentina
}

Recibido: 11/03/2020. Aceptado: 11/09/2020

\begin{abstract}
RESUMEN
La dictadura militar que gobernó el destino de la Argentina en el período 1976-1983 extendió su presencia a múltiples ámbitos de la vida. Las políticas educativas represivas fueron complementadas con la censura directa de textos de literatura infantil. Los temas y la "excesiva imaginación" se consideraron una amenaza para la formación de niños y niñas, y para el orden social que la dictadura perseguía. Paradójicamente, muchos de los mismos textos y escritores prohibidos en aquel momento, son recomendados por el Plan Lector del Ministerio de Educación de la Nación desde el año 2009.

Este informe se propone trazar un arco histórico y literario desde las razones de la censura a las razones del rescate de algunos de los textos de literatura infantil prohibidos durante la dictadura 1976-1983. Desde el punto de vista histórico, expone la situación de la literatura infantil a inicios de la década del ' 70 , los principales acontecimientos de censura de la literatura infantil, y los documentos relevantes de ese periodo relacionados con la educación y la producción literaria. Desde el punto de vista de la literatura, indaga en las nociones de infancia y de literatura infantil y las pone en diálogo. A la luz de este diálogo, se desarrolla un análisis de algunos textos de literatura infantil prohibidos. Esto permite elaborar una interpretación de las distintas actitudes de los gobiernos con respecto a esas obras, y subrayar el valor literario y educativo que en la actualidad se reconoce en ellas.
\end{abstract}

Palabras clave: Literatura; Infancia; Dictadura; Educación; Argentina

\begin{abstract}
The military dictatorship that governed Argentina's destiny from 1976 to 1983 extended its presence to multiple aspects of life. Repressive education policies were complemented by the straight censorship of Children's Literature texts. The subject-matters and the "excessive imagination" dominant in them were considered a threat to children's education and to the social order pursued by the dictatorship. However, many of the forbidden texts are recommended by the Plan Lector (Readers Plan) of the Argentinian Ministry of Education since 2009.
\end{abstract}


This report aims at outlining a historic and literary arch from the reasons for the censorship to the reasons for the recognition of some of these books of Children's Literature prohibited during the dictatorship 1976-1983. From the Historical perspective, it describes the Children's Literature scene in the 1970s as well as give an account of the most relevant acts of censorship and the main documents related with Education and Literary production at the time. From the Literary perspective, it looks into the notion of childhood and Children's Literature, and engage them in dialogue. Guided by this dialogue, we analyse some of the books that had been prohibited. This allows us to interpret the differing governments' attitudes towards those works and highlight the literary and educational value acknowledged in them at present.

Key words: Literature; Childhood; Dictatorship; Education; Argentina

\section{INTRODUCCIÓN}

La dictadura militar que vivió la Argentina en los años 1976-1983 tuvo en su mira también a los niños. El "Plan sistemático de robo de bebés" fue su forma más extrema y cruel. Pero también hubo otras acciones no menos directas cuyo objetivo fue la infancia, tales como aquéllas orientadas a la educación. La "Operación claridad", por ejemplo, con su documento emblemático Subversión en el ámbito educativo (Conozcamos al enemigo), trascendía su ingenua pretensión de "facilitar la comprensión del fenómeno subversivo que vive la Argentina de estos días, especialmente en el ámbito educativo" (p. 6). Más allá de la 'comprensión', tendía tanto a delación de la 'subversión' en ese ámbito, como a la 'prevención' mediante la acción docente que: "por ser tal, debe comprender mucho más que la simple transmisión de conocimientos, como se dijera ha de contribuir a la formación de quienes mañana, con solidez de principios tornarán la antorcha que recibimos de nuestros padres y para que ello sea posible es menester estar preparados" (p. 6). Dicho en otras palabras, atribuía a la acción docente la responsabilidad de ser "custodios de nuestra soberanía ideológica" (Subversión..., p. 60), esto es, de sostener y transmitir a niños y niñas ciertos valores y principios con el fin de erradicar la "grave enfermedad moral (que podríamos denominar "síndrome social')" (Subversión..., p. 59) provocada por el marxismo, y mantener en el futuro el orden moral y social que la dictadura promovía.

Este tipo de acciones 'preventivas' fue complementado con otras acciones directas tales como la censura de textos de literatura infantil, y la presión sobre las empresas editoriales -cuando no, su cierre-. Por caso, el Decreto Nacional 3155/1977 prohibía los libros Un elefante ocupa mucho espacio de Elsa Bornemann y El Nacimiento, los niños y el amor de Agnés Rosenstiehl, y disponía la clausura de Ediciones Librería Fausto (desde luego, éstos no fueron los únicos libros prohibidos, ni la única editorial clausurada, ver listado en Anexo I). Lo interesante es que, en el presente, treinta y dos años después, algunos autores y libros objeto de esa censura son material recomendado para las aulas por el Plan Nacional de Lectura que impulsa el Ministerio de Educación desde el año 2009 (planlectura.educ.ar, ver libros recomendados en Anexo II). Y, en el marco de esas recomendaciones, la literatura escrita en los años '60 y '70 se integra al corpus de obras literarias contemporáneas sin alterar la armonía del conjunto.

En efecto, en los últimos treinta años la literatura infantil ha manifestado una profunda transformación. La explosión del mercado editorial dirigido al público infantil a partir de la década del 90 ha generado nuevas vías de exploración de la realidad que se plasman en los textos que problematizan de modo particular las relaciones entre las palabras, la imagen y las 
vivencias del lector. Desde el inicio del nuevo siglo, esta literatura ha sido recogida por los catálogos de grandes editoriales (Alfaguara, Fondo de Cultura Económica, Océano, por dar sólo algunos nombres). También se interesan por ella editoriales menos extendidas tradicionalmente (Comunicarte, Libros del Zorro Rojo, Edelvives, Quipu, Pípala -la división infantil de Adriana Hidalgo) y editoriales independientes dedicadas específicamente a los libros ilustrados (Limonero). Esto implica una amplia disponibilidad de libros infantiles que presentan un lenguaje pluridimensional y una redefinición de la literatura infantil y de la idea de infancia. Entre la diversidad de escritoras y escritores que se destacan en esta renovación literaria se cuentan, desde luego, autores y autoras de nuestro país.

El rescate de la literatura prohibida durante la dictadura y los rasgos que la equiparan a las formas literarias más nuevas es, pues, el estímulo que inspira el plan de trabajo "La literatura infantil argentina: de la censura a las bibliotecas escolares" en el marco del PI 29A/393-1ICIC-UARG "Literatura, Filosofía y Educación: don y apertura del mundo". La hipótesis que guía la investigación es que los textos de literatura infantil censurados en los años de la dictadura militar (1976-1983) y reivindicados en las políticas educativas nacionales a partir de 2009 presentan una discontinuidad con la concepción dominante de la infancia y la literatura de su época y, en contraste, tienen rasgos consonantes con las concepciones actuales. En este informe nos detendremos en dos aspectos de la investigación realizada: la descripción de la censura de la literatura infantil durante el periodo de la dictadura, y el análisis del corpus seleccionado en el marco de las teorías actuales sobre la literatura infantil y la infancia. El objetivo es reconstruir la censura de la literatura infantil en los años ' 70 en su contexto histórico y político, y explicitar el valor literario y educativo que en la actualidad se reconoce en las obras entonces censuradas.

Con esta investigación se espera realizar un aporte al desarrollo del área de investigación en Literatura Infantil en la UNPA, y al diálogo entre disciplinas, ya que aborda el tema conjugando una perspectiva histórica con una perspectiva literaria. A este diálogo se suman tanto reflexiones en filosofía de la educación como aportes de una didáctica de la literatura infantil que subraya la apreciación estética de los textos.

Para alcanzar estos objetivos se llevó a cabo una investigación bibliográfica sobre la literatura infantil en la dictadura 1976-1983 y una investigación histórica de los documentos oficiales referidos a ella. Para completar este trabajo, se realizó una entrevista a la Dra. Arpes, docenteinvestigadora de la UNPA, cuyas investigaciones constituyen un antecedente relevante en el tema. Por otro lado, se seleccionó un corpus de literatura infantil que cumpliera con los requisitos de haber sido prohibida o censurada, o cuyos autores hubieran sido perseguidos durante la dictadura, y que en la actualidad cuente con la recomendación del Plan Nacional de Lectura. Por último, también se tomaron como marco los desarrollos teóricos y los descriptores elaborados en el marco del Proyecto de Investigación (tanto en el presente como en el anterior, PI 29/A-339 "Filosofía y Literatura en el Nivel Inicial y los primeros años de la Escuela Primaria: la investigación, la práctica y la formación docente").

En el análisis, hemos encontrado que no sólo los textos literarios sino que también las producciones teóricas de autores censurados adelantan rasgos de las concepciones de la literatura infantil y de la infancia contemporáneas. Más aún, son referentes para la producción literaria y también para los lineamientos educativos de las últimas décadas. Asimismo, su literatura coincide con los criterios que se valoran en la literatura posterior al boom de los años ' 90.

En lo que sigue, se ofrecerá en primer lugar una síntesis del estado actual en las investigaciones sobre la censura de la literatura infantil, así como de las investigaciones en literatura infantil y su inserción en el ámbito educativo. Luego, se expondrá el marco teórico, centrado en dos conceptos: el concepto de literatura infantil y el de infancia. En tercer lugar, se hará un recuento histórico de los principales documentos y prácticas de censura durante la 
dictadura. En cuarto lugar, se expondrán los criterios de selección y análisis del corpus. Por último, se expondrá el análisis y las conclusiones obtenidas.

\section{EDUCACIÓN, INFANCIA Y LITERATURA}

\subsection{Marco de referencia Marco histórico}

En la actualidad existe abundante producción sobre la historia de la literatura infantil en la Argentina y, en particular, sobre los libros censurados en el periodo de la dictadura militar: Pesclevi (2014), Arpes y Ricaud (2008), Machado y Montes (2003), Invernizzi y Grociol (2002) que son el punto de partida para la reconstrucción del período y de las acciones de censura y sus consecuencias. Asimismo, algunos escritores que vivieron de cerca la persecución han contribuido recientemente a la formulación de políticas educativas nacionales, la formación docente y la renovación de bibliotecas. Tal es el caso de Graciela Montes (2006), quien ha participado en el diseño de documentos del Plan Lector y otros escritores y revistas que han producido reflexiones sobre la infancia, la literatura infantil, los hábitos lectores, la escuela (Roldán, 2011; Devetach, 2008; Montes, 2001; Revista LIJ, Revista Imaginaria, entre otras).

Por su parte, en el ámbito académico de nuestro país, se han incrementado los espacios que le otorgan un lugar más estable al estudio de la literatura infantil a través del dictado de Seminarios, Especializaciones y Jornadas (Domínguez, 2017). En el mismo proceso, se han multiplicado los estudios académicos sobre la literatura infantil (Carli, 2009), en consonancia con el impulso que el campo recibe en otros países (Colomer, 2010). En la UNPA existen antecedentes en proyectos de investigación: "La parodia en la literatura infantil argentina" (1997-1998), el programa de Investigación "Acerca de esa otra literatura, la literatura infantil" que contuvo dos proyectos "El canon en la literatura infantil" y "La ruptura en la literatura infantil" (1996), que han producido material bibliográfico relevante para este informe (Arpes, 2011; Arpes-Ricaud, 2008; Arpes-Ricaud, 1998; Arpes, 1997). Más recientemente, los proyectos desarrollados por nuestro equipo en la UNPA desde 2015 (supra) han aportado a este desarrollo del conocimiento sobre la literatura infantil y su didáctica.

En este marco, la teoría subraya el potencial intertextual de la literatura infantil, que prioriza el humor y la desmitificación antes que el carácter aleccionador o las estructuras narrativas clásicas de los originarios relatos populares (Colomer, 2010). Asimismo, se enfatiza su conexión con la reflexión filosófica con niños y niñas (Pac y Bahamonde, 2017; Pac, 2017; Pac, Bahamonde y otros, 2016; Medina y Pac, 2016; Bahamonde y Altamirano, 2016; Ramón, 2016; Haynes \& Murris, 2012). Diversos autores tanto del ámbito nacional como del internacional han realizado aportes de análisis de estos nuevos discursos literarios y también han propuesto líneas concretas de abordaje para su trabajo en el aula (Colomer, 2010, Carli, 2009).

Las decisiones conceptuales y teóricas del presente informe siguen estas líneas de investigación.

\section{Marco conceptual}

Infancia

En investigaciones anteriores, hemos encontrado abundantes textos teóricos en los que nos encontramos con 'el niño' o 'la infancia' como conceptos largamente desarrollados y examinados. Entre estas construcciones teóricas y los niños con los que trabajamos ${ }^{1}$ hay,

\footnotetext{
${ }^{1}$ Como parte del Proyecto se desarrolla un taller de literatura y filosofía en el Jardín Infantil de la UARG. Asimismo, las investigadoras desarrollan su función docente en nivel medio y nivel inicial.
} 
siempre, una distancia que impone la elaboración teórica pero que puede y necesita ser tejida con las particularidades de la experiencia en el plano de los conceptos. Porque no podemos suponer que sólo un entramado teórico sea suficiente para nuestra comprensión de la infancia. Para ello, es necesario recorrer la distancia de ida y de regreso entra cada niño en particular y dicha trama de manera periódica, teniendo presente la expresión radical de Graciela Montes: "Me limito a señalar que nuestra sociedad no ha confrontado todavía, serenamente, como el tema merece, su imagen oficial de la infancia con las relaciones objetivas que se les proponen a los chicos, porque una cosa es declamar la infancia y otra muy distinta tratar con chicos" (Montes, 1991, p. 12). Consideramos, pues, que todo intento de describir una 'esencia teórica' de la infancia es una mera declamación de la infancia. En cambio, preferimos aquellos intentos que, aun definiéndola, dejan abierto un espacio para 'tratar con los chicos', es decir, un espacio para que la definición no clausure la experiencia sino que por el contrario esté incompleta sin ella.

En este sentido, rescatamos los lineamientos que proponen despojar al término de su vinculación con la pasividad, la exoneración, la dependencia, como el de Kohan:

Una vez más, no debemos entender la infancia sólo como una edad cronológica. Infante es todo aquel que no habla todo, no piensa todo, no sabe todo (...). Aquel que no piensa lo que ya fue pensado, lo que 'hay que pensar'. Es aquel que piensa de nuevo y hace pensar de nuevo (...) El mundo no es lo que pensamos. 'Nuestra' historia está inacabada. La experiencia está abierta. En la misma medida somos seres de lenguaje, de historia, de experiencia. Y de infancia. (2004, p. 275)

Desde esta perspectiva, la infancia no es una condición natural, sino una construcción que varía con el tiempo y que define un espacio que sí específico, pero cuyas notas no lo encierran en una certeza. De manera análoga a la perspectiva de Kohan, Agamben (2015) define la infancia como un lugar del "no-poder-decir", pero no es por la incapacidad o la necesidad del desarrollo de ciertas capacidades. Por el contrario, es el espacio en el que se hace posible el decir. Dicho en otros términos, es un lugar en el que la realidad no está aún naturalizada. Por ese motivo, al poner en cuestión las certezas sobre las diferencias entre ser niño y ser adulto se relativiza también el carácter de incompletud como rasgo negativo ligado al infante.

De este modo, si bien no podemos apoyarnos en una definición certera y esencial de la infancia, al menos tenemos certezas de qué no es un niño: no es un adulto en miniatura, no es el hombre ideal en potencia, no es una tabla rasa, no es un ser aún irracional que requiere ser educado para devenir racional. Tenemos, también, la certeza de que rechazamos cualquier forma de entender la infancia que les arrebate de las manos la posibilidad de ser 'nuevos', como propone Arendt (2016a, p. 185). Por último, sabemos que los niños no son 'Otros' en el sentido de extraños o ajenos. Compartimos el mundo con ellos y es nuestra tarea como adultos darle continuidad al mundo junto con ellos al tiempo que les hacemos lugar en él, hasta que, eventualmente, esa tarea pase por completo a sus manos.

Así entendida, la infancia es un estado que puede habitar también en el adulto, y que puede perder su lugar en un mundo que obtura la experiencia. Narodowski (1999) plantea que las nuevas estructuras posmodernas provocan la "fuga" de la infancia generando nuevas identidades infantiles, fuga que será hacia dos polos: una infancia procesada a los ritmos vertiginosos de la cultura de las nuevas tecnologías y los nuevos medios de comunicación, que accede a información ilimitada sin depender de un adulto para ello y una infancia excluida, que construye sus propios códigos comunicativos alrededor del aquí y ahora de las calles en las que transcurre su vida, también sin un adulto, en la inmediatez de su necesidad. En medio de estos extremos, transita la tensión entre una infancia de la novedad, en la que emergen naturalmente procesos diferenciales de apropiación de aquello que la rodea, y una infancia donde estos procesos aparecen sesgados por la estandarización y uniformización de la cultura globalizada o de una infancia hipercontrolada. 
El esfuerzo por controlar la infancia, por su parte, no es excluyente de los autoritarismos o las dictaduras. Según Arpes y Ricaud, "la infancia es un territorio de disputas y apuestas de diversos poderes. La familia no es la única que pretende ejercer un control sobre el niño sino que esta función se desplaza también a otra zona, fuera de lo privado, donde se dirimen los intereses de la colectividad" (2008, p.46). En la entrevista realizada, Arpes expande esta idea: La infancia, Adler va a decir que la infancia es el lugar de la felicidad y realización plena del sujeto, es decir la infancia no es una etapa inocente, no es una etapa ingenua de los sujetos ni de las sociedades. La infancia no es un territorio protegido, la infancia es justamente un territorio liberado. Entonces en sí misma como definición, como concepto es un momento amenazante, peligroso y esa es una de las primeras respuestas. Es un territorio liberado y como territorio liberado hay que sujetarlo, rápidamente, y se sujeta muy tempranamente como algo tan básico como es la técnica corporal (...). Y después, porque también está la idea como territorio liberado de la conciencia es pregnante, es decir, recibe todo entonces hay que adoctrinar en ideología, en moral, es decir volver a sujetar ese territorio para que no quede liberado. (M. Arpes, comunicación personal, 22 de mayo de 2019)

Es así que, como territorio de lo posible, de lo no dicho aún, de lo abierto, la infancia requiere de contención al mismo tiempo que corre el riesgo de ser obturado ya sea por el exceso de control explícito, o por la desresponsabilización (Biesta, 2017; Montes, 1998 en Machado y Montes, 2003; (2016[1961] $\left.]^{2}\right)$.

\section{Literatura infantil}

No intentaremos aquí definir la literatura infantil como un 'género' específico dado que ese tipo de caracterización permanecería en un nivel formal, igual que una definición de infancia que omitiera el 'tratar con los chicos'. Qué es la literatura infantil no depende de la edad de los destinatarios sino de cuál sea la concepción de infancia que supongamos. Si, como se dijo más arriba, supusiéramos que un niño es un adulto en miniatura, entonces la literatura infantil sería una versión 'simplificada' del mundo adulto. Si tuviéramos una concepción cronológica de la infancia y, en consecuencia, supusiéramos que es natural y cualitativamente diferente de la adultez, entonces la literatura infantil intentaría tal vez imitar o alimentar ese mundo, seguramente en base a lo que los adultos imaginan o proyectan sobre él. En cambio, si suponemos que la infancia es ese terreno de lo no dicho, entonces nuestra idea de la literatura infantil sería muy similar a nuestra forma de entender la infancia: sería también un espacio de lo posible, en el que el lenguaje y la realidad no están naturalizados; un espacio en el que los sentidos de la cultura se ofrecen y se abren a la novedad; un espacio en forma de historias, descripciones y poemas que conservan y renuevan el mundo al mismo tiempo.

Por ese motivo, damos un lugar importante en todo contexto de educación a la literatura como fuente de experiencia estética y reflexiva, posibilitando desde la polisemia y el lenguaje de la sugerencia la apropiación singular de cada texto. A la vez, la literatura, al prodigar transposiciones, desplazamientos, metáforas, nuevas versiones, problematizadoras y desnaturalizadoras, de lo vivido o conocido, abre camino al encuentro con uno mismo y a la transformación interna a través de la experiencia lectora.

En nuestras investigaciones, hemos desarrollado algunos criterios para seleccionar los cuentos que consideramos representativos de lo que entendemos por literatura infantil, y valiosos para la filosofía de la educación que sostenemos. Estos criterios son, en cuanto al contenido, el potencial reflexivo que resulta de la subversión del sentido común, la capacidad de problematizar conceptos y, desde luego, no tengan finales 'cerrados'. La cercanía con lo que suponemos es el mundo de la infancia siempre está presente, pero en lugar de definir ese

\footnotetext{
${ }^{2}$ Es verdad que a Arendt se le puede criticar su perspectiva desarrollista de la infancia, que aquí rechazamos. No obstante, adherimos a su perspectiva política sobre la educación.
} 
mundo en cuanto a una lista de contenidos 'educativos' (desde lavarse los dientes hasta compartir los juguetes) juega con ese mundo, explora sus posibilidades, expande sus horizontes. Como se dijo antes, si la infancia es un espacio en el que la realidad no está aún naturalizada, la literatura infantil será un espacio que acompañe el proceso de conocimiento del mundo pero que evite, al mismo tiempo, una naturalización absoluta.

En cuanto a la forma, los criterios priorizan el uso poético del lenguaje, los libros que proponen formas novedosas de la imagen y la ponen en diálogo con el texto de modo que no se trate ni simplemente de un texto lineal con hermosas ilustraciones, ni de un texto que propone rupturas acompañado por ilustraciones estereotipadas. Por último, un criterio fundamental es que la literatura se resista a la instrumentalización, esto es, que la experiencia literaria que responde a los criterios previos no se obture al subordinarse a la enseñanza o la moraleja. Es verdad que, cuando leemos literatura aprendemos indefectiblemente: nuestras experiencias, nuestra sensibilidad, nuestro horizonte cultural y linguístico se amplían y se enriquecen. Este es justo uno de los motivos por los cuales se la incorpora a la escuela. Pero no es lo mismo una lectura que intenta moralizar, imponer ideas, saberes, hábitos o formas de comportamiento, que un texto que promueve el aprendizaje simplemente por ser sugerente, provocador, movilizador del universo personal mediante la puesta en juego de la imaginación, de la sensibilidad, del gusto, de las percepciones, de los sentimientos.

\section{Marco teórico}

Una de las líneas teóricas del Proyecto que se retoma en este trabajo es la filosofía de la educación de Biesta (2017). Su postura remite a la filosofía política y de la educación de Arendt y Rancière. La relevancia de su propuesta radica en que su concepción de la educación es, al mismo tiempo, una concepción de la sociedad y de las relaciones políticas. En efecto, Biesta propone que el aprender nunca se da 'en el aire' sino que siempre se aprende algo (un qué), de alguien (un quién) y por algo (con un porqué). En el ámbito escolar, el alguien de quien se aprende es el docente, pero la educación no se limita necesariamente a la escuela y a la acción docente. Esto aparece con más claridad cuando se examinan el qué y el porqué de la educación. El qué es definido por Biesta como 'la verdad'. Pero esta verdad no es 'científica' o semántica, es decir, no consiste en un conjunto de proposiciones que son verdaderas porque coinciden con las cosas. En este punto, Biesta propone una distinción entre "lo teórico y lo existencial, es decir, entre lo que es verdad y lo que importa" (2017, p. 73, nuestro énfasis). Eso que importa es aquello a lo que decidimos y conseguimos "hacer sitio en mi existencia" (2017, p. 73) para darle a esta última una forma y un sentido.

Esta manera de entender la verdad como el qué de la educación, por su parte, es solidaria con el porqué: el propósito de la educación es, en su sentido fundamental, compartir el mundo, construir una manera de existir en el mundo, de "sentirnos en casa en el mundo y [compartirlo con] los desconocidos" (Biesta, 2017, p. 139). Si pensamos en la Literatura, que es el objeto privilegiado de este trabajo, su enseñanza en las escuelas y su presencia en la sociedad, no sería simplemente una línea en una currícula o en un plan de gobierno. Que la Literatura sea parte de la vida escolar y social es una decisión sobre las experiencias que dan sentido una forma de vivir con los demás. Y decidir que un tipo en especial de Literatura puede o no puede tener presencia en las escuelas y la sociedad, es una decisión sobre una clase particular de relaciones sociales. En la historia de nuestro país, la dictadura es un ejemplo claro de cómo la relación con la Literatura fue controlada y censurada en la educación y en la sociedad como una forma de construcción del mundo y de un modo de existir en él: "la coerción de la dictadura se traduce en acciones concretas sobre los cuerpos individuales y sobre el cuerpo social" (Arpes y Ricaud, 2008, p. 70), en su materialidad y en su aspecto simbólico. Pero también tenemos ejemplos de cómo, años más tarde, el 'rescate' de esa Literatura persigue 
también la constitución de un modo de existir en el mundo que se contrapone a aquél, y que consideramos de mayor libertad.

A su vez, ese gesto de censura responde a un gesto análogo a la decisión sobre lo que importa e, incluso, tal vez más fundacional. Es el "reparto de lo sensible" (Rancière, 2000), la distribución de espacios y tiempos, la visibilización/invisibilización en que consiste la 'estética política'. "La política trata de lo que vemos y de lo que podemos decir al respecto, sobre quién tiene la competencia para ver y la cualidad para decir, sobre las propiedades de los espacios y los posibles del tiempo", dice Rancière (2000, p. 10). Y este reparto supone y define relaciones en las que se hace posible la aparición de los otros, que Arendt denomina "pluralidad". Relaciones que hacen real al mundo al conversar sobre él con otros, y al vivir con otros en él. Sólo en ellas es posible la acción (cf. Arendt, 2016b, pp. 79-80), nos constituimos como sujetos y podemos aportar novedad al mundo. En esta posibilidad, siguiendo a Arendt, radica la libertad. Por el contrario, el totalitarismo es la destrucción de las relaciones y, por tanto, la destrucción de la pluralidad.

En cuanto a la literatura infantil, el marco teórico se apoya en las nuevas tendencias en literatura infantil. Existe actualmente una proliferación de literatura para niños que, en consonancia con nuestro tiempo, desestabiliza la noción de literatura infantil como género que se desarrolló durante mucho tiempo entre lo ingenuo y lo predecible. Así, ofrece novedosas vías de exploración de la realidad, poniendo en entredicho las tradicionales relaciones entre el lenguaje y aquello que éste refiere, haciendo emerger preguntas sobre cuestiones lingüísticas, culturales, filosóficas que problematizan las representaciones acerca del mundo, habilitando la discusión (Colomer, 2010; Carli, 2009). Esto implica que entendamos que el libro no es sólo una herramienta o un medio, sino un puente entre subjetividades, un puente hacia el otro y hacia lo otro, lo distinto (Andruetto, 2012).

La experiencia con la literatura define un modo de existir en el mundo (Petit, 2014). Por su parte, cierta literatura actual constituye un fuerte estímulo para la reflexión y la constitución de la subjetividad (Petit, 2016; Turin, 2014; Haynes y Murris, 2012). Estos valores de la literatura infantil estará supuesto en nuestro acercamiento a los textos que son objeto de nuestra investigación. También será nuestro criterio para identificar lo que, con mucha cautela, denominamos 'calidad literaria'. Entendemos que éste es un concepto difícil de definir, un concepto que nos pone frente al riesgo del dogmatismo entendido como una actitud que clausura las posibilidades a nuevos sentidos. En efecto, consultada por los criterios de calidad literaria, Arpes manifiesta:

el tema de la calidad literaria es un problema para los estudios literarios, cómo se juzga la literatura, tendrías otros principios para juzgar la calidad literaria: cómo responde esa literatura a las demandas que tienen vigencia en su presente y ese es otro principio que podría tomarse como buena literatura es un texto que responde a su presente, responde desde el lenguaje a su presente, responde desde su sistema temático a su presente, responde desde su retórica a su presente y ahí podría decirse es un texto de su presente. (...)

Borges [dice que] una buena literatura es capaz de inventar, la invención. De habilitar un mundo posible, sumamente verosímil y ahí no está en juego ni el capital cultural del autor, no está en juego el sistema de circulación, la alta literatura, la literatura popular, la literatura de la massmedia, la literatura tecnológica, no está en juego el lenguaje, cuánto más bello o menos bello, cuanto más estetizado o menos estetizado sea el lenguaje. Y eso es un criterio de calidad, aquel que tiene la capacidad de inventar un mundo posible por más alejado del paradigma de la realidad y yo creérmela, y ese es un principio de calidad. (M. Arpes, comunicación personal, 22 de mayo de 2019)

Es así que la capacidad de invención de la literatura, en consonancia con nuestra manera de entender la infancia, es también una ocasión para inventar una manera de existir en el mundo. 
Cabe aclarar, por último, que sabemos que esa invención que no es ingenua. Esa invención supone una decisión por lo que importa, una responsabilidad por el mundo y el amor por los niños que Arendt exige para la educación (Arendt, 2016a).

\subsection{Resultados análisis y discusión}

\subsubsection{Dictadura, infancia y literatura}

La explosión de la literatura infantil de los años '90 no fue, ciertamente, la primera en nuestro país. Arpes y Ricaud relatan que

a fines de los '60 la infancia se configura como objeto de mercado y la industria editorial comienza a regular la producción para dicho mercado editando los textos que la escuela demanda, la clásica literatura de tradición popular o las adaptaciones de la literatura universal y, finalmente, poniendo en circulación esta novedosa escritura de textos literarios pensada específicamente para el público infantil. (Arpes y Ricaud, 2008, p. 19)

Con respecto a esta última, Montes señala que la década del '60 asistió a una suerte de revolución en la literatura infantil. La producción destinada a los niños, a la que califica como "literatura "de escuela", hacía un uso del lenguaje "que resultaba muy poco significativo desde el punto de vista literario" (Montes, 1998 en Machado y Montes, 2005, p. 66) porque: "había en esos cuentos de 'niños como tú' (o de animalitos que hacían las veces de 'niños como tú'), en esos 'ejemplos morales', en esa recreación 'culta' de leyendas, en todas esas lecciones embozadas, algo que los volvía ajenos" (p. 66).

En ese marco, la aparición de María Elena Walsh y de Javier Villafañe marcó un quiebre en lo que hace a la literatura infantil. María Elena Walsh, subraya Montes, provenía de la literatura y la música -no "de la escuela"-, y tenía un contacto cercano con una literatura infantil lúdica (como las nursery rhymes). Javier Villafañe, titiritero, relataba poemas y cuentos sencillos y poéticos (Montes, 1998 en Machado y Montes, 2005, pp. 66-67). En el transcurso de esa época se sumarían escritoras como Laura Devetach, Elsa Bornemann, Gustavo Roldán, Ema Wolf, y proyectos editoriales como los Cuentos de Polidoro (del Centro Editor de América Latina) y los Cuentos del Chiribitil (de la Editorial Colihue).

Montes describe a este grupo de escritoras y escritores como sigue:

En general veníamos de la literatura, es decir, que éramos lectores, y, cuando escribíamos, teníamos ilusiones de literatura y no de escuela. Hacíamos entrar en el imaginario otro tipo de historias. Nos negábamos a las moralejas. Nos gustaba urticar. No éramos solemnes. Recurríamos al humor. Y usábamos otro tipo de lenguaje. Un lenguaje cercano, menos neutro y más propio, más vital. (Montes, 1998 en Machado y Montes, 2005, p. 68)

En el contraste que subraya Montes entre la literatura infantil previa a esta época y la de este primer boom literario en la Argentina, se percibe con claridad la diferencia en la concepción de la infancia. Pero, sobre todo, al margen de la postura política de los escritores, se percibe una definición con respecto a la política de la infancia. En efecto, al referirse a la infancia como territorio que, por liberado y amenazante, hay que controlar, Arpes concluye:

Y me parece que esa es la respuesta que tengo para pensar en que la literatura infantil en momentos de violencia política, no necesariamente dictaduras, momentos de mucha exasperación social, en momentos de control social y violencia política-institucional la infancia, el sujeto niño o niñe, y todo lo que hace a su mundo y a su universo tiene que controlarse eso lo hacemos los padres con sus niños, lo hace la escuela con sus alumnos, lo hace el estado con políticas de infancia y nosotros tenemos actualmente los debates en torno a la identidad de género que son un nuevo sistema de infancias liberadas que deben ser controladas. (M. Arpes, comunicación personal, 22 de mayo de 2019)

Como se verá un poco más adelante, los libros prohibidos participaban de los rasgos propios de esta nueva literatura. 
Desde luego, el compromiso con la realidad social de la Argentina era también un rasgo que compartían. En este sentido, Montes resalta que "veníamos de unos años de mucha rebeldía, huelgas fuertes y cuestionamiento de la propiedad privada" (1999 en Machado y Montes, 2005 , p. 108). Y, si bien en todo momento la escritora subraya que "la materia" de la literatura siempre es el lenguaje y la palabra, "la escritura [también está hecha] de otras cosas" tales como "temas, miradas sociales, imaginarios de variada procedencia" (Montes, 1999 en Machado y Montes, 2005, p. 84).

En estos compromisos se evidencian las decisiones por lo que importa, las elecciones de la clase de mundo que inventamos para vivir juntos. Es claro que, como se ha dicho, esta decisión no es ingenua. Con todo, por sí mismo esto no define el sentido político de la literatura. Según Arpes,

la dimensión política de la literatura es el uso político de la literatura, sus usos. La literatura en sí misma no tiene una declaración política, en todo caso la tendrán sus autores, la tendrá su sistema de linaje y filiaciones, pero en sí misma la literatura no es política, sí existe un uso político de la literatura que además no tiene estrictamente que ver con la dimensión ideológica o la praxis política. (M. Arpes, comunicación personal, 22 de mayo de 2019)

Las obras prohibidas y las obras seleccionadas en este trabajo, pues, son políticas pero no necesariamente porque en ellas se cuestione (o se defienda, en algún otro caso) la propiedad o la autoridad, porque en ellas se explore el mundo del trabajo y la explotación. Lo son en función del juego de relaciones en el que circulan. Y, de hecho, se verá que los motivos para la prohibición no es solamente esas referencias temáticas sino, precisamente, la politización de la creación de mundos, esto es, de lo literario en ellas y la politización de la infancia.

\subsubsection{Dictadura}

La última dictadura militar en Argentina vulneró la totalidad de los derechos humanos incluyendo los que se encuentran en relación a la cultura. La sistematicidad de las acciones dictatoriales no sólo estuvo destinada a la desaparición de personas, sino a todo aquel ámbito donde la ideología 'subversiva' pudiera llegar. La represión a la cultura es también una represión política que produce un daño a nivel colectivo y en las subjetividades individuales, privándolo a las personas del acceso a los bienes a los que tiene un derecho inapelable (Invernizzi y Gociol, 2002, p. 22). En este sentido, coincidimos con la hipótesis defendida por Invernizzi y Gociol que considera a la cultura como una preocupación clave en el plan dictatorial, cuyo control se llevó adelante una estrategia de alcance nacional (2002, p. 13), que describen como sigue:

De un lado se estaban los campos de concentración, las prisiones y los grupos de tareas. Del otro, una compleja infraestructura de control cultural y educativo, la cual implicaba equipos de censura, análisis de inteligencia. (...) Dos infraestructuras, complementarias e inseparables en su concepción. Dos caras de la misma moneda. (Invernizzi y Gociol, 2002, p. 23)

La dictadura tenía identificado un 'gran enemigo de la nación': el socialismo. Éste funcionaba como un gran paraguas que abarcaba toda forma de pensamiento que catalogaba como 'subversión'. La subversión ponía en riesgo a la nación y los valores que identificaban al gobierno militar, y debían prevalecer en ella: la moral cristiana, la tradición nacional y la dignidad de ser argentino. A su entender, la cultura era el modo en que trabajaban estas ideas socialistas dentro de las mentes de los ciudadanos de todas las edades.

El proyecto que llevaban adelante era global, se diría que 'fundacional' (de ahí el nombre de 'Proceso de Reorganización Nacional'), y en él lo cultural ocupaba un lugar central y básico. Los mismos enunciados de los voceros del poder dictatorial dejaban en claro que la 'guerra' también era cultural, y como tal merecía su propia estrategia. (Invernizzi y Gociol, 2002, p. 31) 
Los trabajos de inteligencia dirigidos contra lo cultural, se extendieron al sistema educativo en general y, en particular, a la literatura. En efecto, luego de una gran explosión en los años '50 y ' 60 , el mercado literario argentino se vio duramente afectado por las medidas tomadas por el Poder Ejecutivo Nacional de la última dictadura militar.

De los documentos, públicos y secretos, emitidos por el gobierno militar se puede dilucidar la importancia que le brindaban como difusores de una ideología. En este marco, es que la literatura infantil se vuelve en uno de los espacios más vigilados por el ojo censor. Se sentía la obligación moral de 'preservar' a la niñez de aquellos libros que pudieran poner en riesgo la transmisión de valores que vayan en contra de lo que ellos consideraban -familia, la religión y la patria-. (Invernizzi y Gociol, 2002, p. 110)

En consecuencia, se hicieron comunes las (sorprendentes) 'listas negras' de literatura infantil que incluían varias editoriales que fueron forzadamente cerradas, escritores perseguidos, y colecciones y libros censurados.

En el sistema educativo, tanto a nivel primario como secundario, el Ministerio de Educación puso en marcha el 'Operativo Claridad'. En el año 1978 con el Decreto 507/78 se impulsaron acciones que comprendían el seguimiento del personal docente y no docente, así como de directivos y estudiantes e, inclusive, el control del material escrito que se utilizaba en las escuelas. "Este conjunto de operaciones de espionaje e investigación dio lugar a inhabilitaciones, cesantías, encarcelaciones, torturas y desapariciones" (Pesclevi, 2011, p. 125). Uno de los documentos correspondientes a este operativo, la Directiva del comandante en Jefe del Ejército $\mathrm{N}^{\circ} 507 / 78$ ratifica que:

... interesan fundamentalmente aquellos informes referidos a funcionarios y directivos, que mediante acción o inacción favorecen a infiltración así como de docentes religiosos o laicos que impriman a sus clases una clara o encubierta orientación marxista. (en Invernizzi y Gociol, 2002, p. 108)

Puede considerarse que estos operativos, además de la represión misma que implicaron sobre las personas, buscaron manipular lo que de algún modo iba a alojarse en la memoria colectiva de la sociedad argentina, constituyendo una determinada identidad y evitando firmemente la constitución de otras identidades y otras puertas hacia el futuro que, desde la democracia, no podemos sino considerar más libres.

\subsubsection{La literatura censurada}

Los títulos que fueron censurados en el período de la última dictadura militar son realmente muchos. Pesclevi ha reunido estos títulos en un invalorable libro-catálogo publicado hace una década y más recientemente reeditado (a partir del cual se ha elaborado el listado del Anexo I). Con todo, Pesclevi advierte que "Es importante tener en cuenta que, si bien existían numerosas listas 'oficiales' en relación a aquellos libros censurados, diversos libros se encontraban prohibidos pero no por escrito. Eran víctimas de una censura difusa, y podría dejarse entrever una clara intención de empujar a los escritores a una 'autocensura"' (2014, p. 41).

También Invernizzi y Gociol hacen referencia a las prohibiciones indirectas, conocidas por los docentes que sabían que existía un material que no podía utilizarse. En efecto, "dado que circulaban los listados de libros permitidos, los autores que no figuraban automáticamente quedaban prohibidos; por omisión si no eran autorizados eran censurados. Era otra lista negra" (Invernizzi y Gociol, 2003, p. 108). Por último, esta censura no expresada en palabras, es descripta por González en su Prólogo a este trabajo como expresión del miedo:

la censura estatal es una parte oscura del miedo que opta por hablar. Es cierto que otras formas de miedo llevan a la mudez, a la rigidez de los cuerpos, al apagamiento de zonas enteras de la memoria. Pero cuando la censura elige ponerse las vestimentas del lenguaje 
reglamentario del Estado, escribe en una página singular del poder, que acaso después quiere borrar. (en Invernizzi y Gociol, 2002, p. 13)

Recorrer estas listas es recorrer nombres familiares ya sea por la experiencia infantil o por la experiencia profesional. Muchos de ellos, como se dijo, son títulos recomendados por el Plan Nacional de Lectura en cuya sección 'Libros de memoria viva' (http://planlectura.educ.ar/?p=897) se rinde homenaje a los libros censurados y editores y escritores perseguidos. Dada la cantidad y la variedad de las obras prohibidas, y la dificultad de acceso a la documentación fehaciente sobre la prohibición de algunas de ellas, en este trabajo nos limitaremos a cuatro de ellos: Un elefante ocupa mucho espacio, de Elsa Borneman, La torre de cubos y La planta de Bartolo, ambos de Laura Devetach, y Los zapatos voladores, de Margarita Belgrano.

Un elefante ocupa mucho espacio fue publicado por primera vez en Buenos Aires por Ediciones Librerías Fausto en 1975. Era el segundo número de la colección La Lechuza, y tenía ilustraciones de Ayax Barnes ${ }^{3}$. El libro fue prohibido mediante el decreto del 13 de Octubre de 1977 N³155 junto con El nacimiento de los niños, los niños y el amor de Agnés Rosenstiehl, argumentando que de los relatos:

surge una posición que agravia a la moral, a la familia, al ser humano y a la sociedad que éste compone. Que ambos casos, se trata de cuentos destinados al público infantil, con una finalidad de adoctrinamiento que resulta preparatoria a la tarea de captación ideológica del accionar subversivo (Decreto 3155/1977, Poder Ejecutivo Nacional).

Es claro el modo en que Un elefante ocupa mucho espacio busca la empatía del lector con respecto a la explotación que sufren los animales del circo. El punto de Víctor, el elefante protagonista de la historia, es claro: debe organizarse una huelga general. Y propicia el debate con sus compañeros de circo para llevarla a cabo. Algunos de ellos encuentran la idea como un completo disparate, pero hay algo en lo que Víctor es muy claro e insistente: la libertad.

-¡Al fin una buena pregunta! -exclamó Víctor, entusiasmado, y ahí nomás les explicó a sus compañeros que ellos eran presos... que trabajaban para que el dueño del circo se llenara los bolsillos de dinero... que eran obligados a ejecutar ridículas pruebas para divertir a la gente... que se los forzaba a imitar a los hombres... que no debían soportar más humillaciones y que patatín y que patatán. (Y que patatín fue el consejo de hacer entender a los hombres que los animales querían volver a ser libres... Y que patatán fue la orden de huelga general). (Un elefante ocupa mucho espacio, edición de 1975, p.4)

El cuento propone la reflexión sobre conceptos como los derechos civiles y lo que ocurre cuando son vulnerados, la libertad, los derechos humanos. Por otro lado, nos pone frente al concepto de trabajo, huelga general, la organización en las protestas sociales, los sindicatos. Siendo que el sindicalismo fue perseguido por la dictadura, no es de sorprender que también Víctor fuera perseguido... Desde luego, éstos son conceptos que es necesario también pensar en democracia dado que, más allá de las formas institucionales, en los hechos nunca pueden ser dados por supuesto.

Por su parte, La torre de cubos de Laura Devetach, lleva el mismo nombre que la antología que lo contiene, de la que también es parte La planta de Bartolo. Editado por primera vez en 1973 por Librerías Huemul, el libro fue censurado por la Resolución $\mathrm{N}^{\circ} 480$ del día 23 de

\footnotetext{
${ }^{3}$ Ayax Barnes fue ilustrador de la Colección Polidoro, cuyos títulos también fueron objeto de la censura durante la dictadura. También fue ilustrador de otros libros prohibidos, cuya autora fuera su esposa, Beatriz Doumerc: $\mathrm{La}$ línea (publicado en 1975 y prohibido por Decreto 3155 de 1977), El pueblo que no quería ser gris (editado en 1975 por Ediciones Rompan Fila, y prohibido por el decreto 1888 de 1976 (Dirección de Cultura y Educación de la Provincia de Buenos Aires)), y Una pluma con historia (prohibido por Decreto 3155 en el año 1977, reeditado en 1990 por Edelvives y en 2017 por Colihue).
} 
mayo de 1979 en Santa Fe y luego, como efecto dominó, la prohibición se extendió a Mendoza, Córdoba y Buenos Aires (Pesclevi, 2015, p. 75). Entre los motivos que detallan su censura se encuentra, por un lado, que de la obra "se desprenden graves falencias tales como simbología confusa, cuestionamientos ideológicos-sociales, objetivos no adecuados al hecho estético, ilimitada fantasía, carencia de estímulos espirituales y trascendentes", y por otro lado, que algunos de los cuentos terminan "cuestionando la vida familiar, distorsas (sic) y giros de mal gusto, la cual en vez de ayudar a construir, lleva a la destrucción de los valores tradicionales" (Resolución N480, Santa Fe en Invernizzi y Gociol, 2015, p. 311).

Estos argumentos combinan razones temáticas con motivos estéticos. Como subraya Arpes:

la literatura masiva, las prácticas literaria dentro de la massmedia, fue el blanco más atacado por los mecanismos represivos y dentro de ellas la literatura infantil. Con criterios que no son estrictamente políticos, porque si uno lee detalladamente y detenidamente los argumentos de los decretos de prohibición ahí se apela a una prohibición de esa literatura no porque este ideologizada sino porque lo cito literal 'hay un exceso de fantasía que perturba la mente de los niños', 'hay un exceso de mundo mágico', es decir, son criterios estéticos los que priman paras censurar esa literatura. No es porque su autor es del PC o porque se incentiven los textos a una revolución social o a tomar las armas nada eso, es decir que ahí hay un sistema interesantísimo desde el punto de vista sociológico e ideológico que es censurar tal literatura por criterios que son literarios y por principios que son inmediatamente estéticos. Por supuesto que nosotros sabemos, porque estuvimos en contacto con los autores, que sus autores estuvieron perseguidos y exiliados eso no se puede soslayar. Pero es un terreno de vínculo entre violencia política y literatura muy peculiar el de la literatura infantil porque el propio sistema represivo apela a criterios de censura estéticos. (M. Arpes, comunicación personal, 22 de mayo de 2019)

En una primera lectura, el cuento La torre de cubos puede resultar el relato de una simple ensoñación y no proponer desafío alguno a la reflexión. Lo cierto es que en un análisis más profundo nos encontramos con una niña sola, un extraño que ingresa a su casa, y el ingreso al mundo de los caperuzos, situaciones que dan qué pensar. Luego, ya dentro de este mundo se encuentra con una situación que le llamó particularmente la atención: eran felices. Todo lo hacían muy alegres, en familia, acompañados:

Irene se sentía feliz allí. El olor a pan y durazneros le llenaba el cuerpo. Las casitas caperuzas eran pepitas de luz suspendidas entre las colinas. Cuando regresaran a casa le diría a mamá que tratasen de vivir como los caperuzos; así de contentos, por lo menos. Le diría a papá que de vez en cuando secasen entre los dos los platos, hiciesen tortas morenas cubiertas de azúcar, y echasen a mamá de la cocina, para luego darle una sorpresa. ¡Tenía tantos papeles en su portafolio, papá! ¡Y hablaba siempre de cosas tan serias! Y así no podían estar contentos. Papá estaba muy poco en casa. (Devetach, 2006, pp.18-19)

Irene invita a imaginar, a un 'exceso de imaginación' donde todo marcha de modo ideal, cuestiona en pocas líneas la situación de su familia donde por ejemplo la mamá siempre se encuentra en la cocina y el papá continuamente habla de cosas serias y no tiene un momento para divertirse y pasar tiempo en la casa. Cuestiona la vida del adulto, el formato de familia vigente para aquel entonces y quizás hasta el presente. Abre la posibilidad de que los estudiantes expresen si alguna vez se sintieron Irene, o soñaron con su propio mundo de caperuzas (tal vez con otro nombre o con otras características), y por qué consideran que estos sueños que dan lugar a la imaginación pueden haber 'incomodado' al gobierno militar.

La misma edición de La torre de cubos, contenía el cuento La planta de Bartolo. Un día, Bartolo plantó un cuaderno y, en el macetón, creció una planta que daba cuadernos. Los cuadernos eran muy caros, así que Bartolo empezó a regalarlos a los chicos. Claro, el vendedor de cuadernos no estaba contento con la situación: 
Un día, fumando su largo cigarro, fue caminando pesadamente hasta la casa de Bartolo. Golpeó la puerta con sus manos llenas de anillos de oro: ¡Toco toc! ¡Toco Toc!

-Bartolo -le dijo con falsa sonrisa atabacada-, vengo a comprarte tu planta de hacer cuadernos. Te daré por ella un tren lleno de chocolate y un millón de pelotitas de colores.

-No -dijo Bartolo mientras comía un rico pedacito de pan.

-¿No? Te daré entonces una bicicleta de oro y doscientos arbolitos de navidad.

-No.

-Un circo con seis payasos, una plaza llena de hamacas y toboganes.

-No.

-Una ciudad llena de caramelos con la luna de naranja.

-No. (La planta de Bartolo, p. 7)

Todo lo que el vendedor de cuadernos ofrece a Bartolo es tan fantasioso como la misma planta de cuadernos. La negociación tiene el tono del 'disparate' (Origgi, 2014) o del 'absurdo fantástico' (Cabrera Delgado, 2014), al estilo de los que propone con frecuencia María Elena Walsh. No obstante, al interior de la historia, son cosas que verosímilmente pueden resultar tentadoras para Bartolo, pero que no acepta.

Este tono resalta el contraste con la respuesta del vendedor de cuadernos que, con todo, mantiene la atmósfera lúdica y la verosimilitud puramente literaria en el uso de los diminutivos y la descripción directa, 'desdramatizada' podemos decir, de la resolución de la situación:

Al rato (el vendedor) volvió con los soldaditos azules de la policía.

-¡Sáquenle la planta de cuadernos!- ordenó. Los soldaditos azules iban a obedecerle cuando llegaron todos los chicos silbando y gritando, y también llegaron los pajaritos y los conejitos. Todos rodearon con grandes risas al Vendedor de Cuadernos y cantaron 'Arroz con leche', mientras los pajaritos y los conejitos le desprendían los tiradores y le sacaban los pantalones. (La planta de Bartolo, p. 7)

Chicos, pajaritos, conejitos. Todos efectivamente vulnerables pero armados con risas y cantos que los hacen más fuertes que el vendedor de libro y los soldaditos azules. La autoridad es vencida, pero no oponiéndole violencia. Por el contrario, la autoridad es 'desarmada' mediante el juego y la risa, y estrategias colectivas de construcción de comunidad, una vez más, al estilo de 'El Gato que pesca', 'El reino del revés' y otros poemas de María Elena Walsh.

Por último, Los zapatos voladores, de Margarita Belgrano, ofrece un ejemplo análogo. Este texto fue editado por primera vez en 1977, el número 9 de la colección Los Cuentos del Chiribitil, del Centro Editor de América Latina, con ilustraciones de Chacha (cabe recordar que en 1980 el gobierno llevó a cabo una quema de los libros de ésta y otras colecciones del CEAL). En él, los zapatos que el cartero arroja por su ventana, cansado de caminar, provocan sorpresa y fascinación en los habitantes de la ciudad. El único ajeno a la excitación por los zapatos voladores es el gobernador, a quien preocupa el 'desorden'. Cuando el cartero finalmente explica que le dolían los pies y que arrojó sus zapatos enojado por esa injusticia, se produce el siguiente diálogo:

-¿Ajá?-contestó el gobernador a punto de perder la paciencia-. ¿Así que el dolor de pies es una injusticia? ¿Para escuchar semejante tontería estoy perdiendo mi valioso tiempo?

-La injusticia es tener que caminar...

$\ldots$

-¿Y por qué no se compra un triciclo, una bicicleta o un borrico?

-Porque mi sueldo de cartero no me alcanza, señor gobernador (...) (Los zapatos voladores, $\mathrm{p}$.

22) 
El gobernador promete crear una comisión investigadora del caso. Pero la gente no escucha su discurso de promesas; junta monedas y le compra una bicicleta al cartero. Es así que la comunidad desarma a la autoridad sin violencia, mediante una acción colectiva, como la de los animales del circo en Un elefante ocupa mucho espacio.

Esta selección de pasajes puede, sin dudas, ser ampliada. No obstante, los rasgos señalados nos acercan al objetivo propuesto. En los cuatro textos reseñados aparecen características que, como se dijo más arriba, se combinan de manera armónica con la literatura infantil contemporánea y pueden adscribir a un concepto de infancia como el propuesto en este trabajo.

En primer lugar, su potencial reflexivo. Todos ellos tratan con conceptos que, siguiendo a Splitter y Sharp (1995) podemos llamar filosóficos por ser comunes a la experiencia de todos, centrales en dicha experiencia y discutibles o abiertos, es decir, nunca agotan su sentido. La familia, el trabajo, la autoridad, la propiedad, la imaginación, la soledad, la comunidad, todos ellos se problematizan en los cuentos seleccionados. Y subrayamos la idea de la problematización por sobre la moralización. Los relatos terminan con un regreso a la vida cotidiana de cada personaje, o con situaciones que muestran el triunfo de los personajes rebeldes en el mismo marco lúdico e 'irreal' que se señaló al analizarlos. Víctor y los animales del circo, volvieron a sus respectivos lugares de origen en avión (aunque Víctor tuvo un avión para sí mismo, porque "un elefante ocupa mucho espacio". Irene "arrojó un beso para los caperuzos" y corrió al encuentro de su mamá, no sin la esperanza de transformar su mundo en uno semejante al de los caperuzos. El Vendedor se fue "a la carrera hacia el lugar solitario donde los vientos van a dormir cuando no trabajan". El cartero se compró la bicicleta "y un lindo par de zapatos nuevos", y siguió repartiendo cartas. Ninguno de los relatos expone un 'mensaje' mostrando alguna enseñanza que adquirieron los personajes, o alguna lección que le dieron a otros. Ninguno explicita una moraleja, un mensaje aleccionador, como conclusión del relato. Por caso, los dueños del circo liberaron a los animales porque se agotaron de andar en cuatro patas, caminar sobre las manos, rebuznar y rugir. En ningún momento se dice que el circo haya cerrado. En ningún momento el dueño del circo enuncia que está mal encerrar a los animales. Este rasgo define su potencial para la reflexión filosófica, porque se combina con otro: su calidad literaria.

La calidad literaria es, en segundo lugar, una característica que estos relatos comparten. El lenguaje es directo y poético al mismo tiempo. Por un lado, no temen usar expresiones tales como "con falsa sonrisa atabacada" (La planta de Bartolo). El estilo directo en que presentan los 'hechos' del relato no es lo mismo que un vocabulario simplificado. Por otro lado, todos los textos contienen belleza, en ocasiones en frases dichas casi al pasar, como en los ofrecimientos del Vendedor a Bartolo, en las descripciones detalladas de La Torre de Cubos. Hasta el zapato enganchado en la antena de televisión resulta poético en Los zapatos voladores.

Este uso de lenguaje, esta belleza del lenguaje, se combina, a su vez, con el humor. La oferta de 'doscientos arbolitos de navidad', combina la imagen de esos arbolitos con sus millones de lucecitas titilando con lo absurdo de la oferta. Asimismo, como hemos señalado, el humor, las situaciones lúdicas, el disparate, son un recursos que, en estos relatos, desarman a la autoridad. Por último, tanto la belleza como el humor contribuyen al clima de irrealidad, a la imaginación 'excesiva'.

Finalmente, es necesario subrayar la capacidad de estas historias para crear mundos, inventar sentidos y formas de existir en el mundo. Es verdad que no proponen cualquier mundo, que los mundos que sugieren tienen características y valores identificables. Pero, como señalamos, no lo hacen al modo de una moraleja, no lo hacen obturando la posibilidad de compararlos con otros mundos. Por el contrario, habilitan el enriquecimiento de la experiencia, otro rasgo 
que acentúa su potencial reflexivo. No importa si los lectores Bornemann se dedican al sindicalismo, o si los lectores de Devetach y de Belgrano terminan siendo Bartolos o Vendedores, carteros o gobernadores. Lo que cuenta es que la experiencia del mundo, los sentidos que leemos en el mundo, la manera como podemos imaginar nuestro lugar en el mundo no es la misma después de las lecturas; es más rica. El uso político de esta literatura combate o estimula esa riqueza.

\section{CONCLUSIONES}

El Plan de Trabajo de la beca de investigación se originó a partir del hecho de que los mismos libros censurados por la dictadura militar en la Argentina son, en la actualidad, recomendados para su lectura en las escuelas. A diferencia de la sensación de ruptura con la literatura infantil anterior a los años ' 60 , la lectura y el análisis de estos cuentos manifiestan una cierta continuidad con la literatura infantil y la idea de infancia valorada en la actualidad.

El informe presentado se basa en una pequeña muestra de aquellos textos, y la selección estuvo orientada por la búsqueda de dicha continuidad. Considerando el reciente relanzamiento del Plan Nacional de Lectura en diciembre de 2019, el análisis puede prolongarse con las nuevas concepciones de la infancia y la literatura en él presentadas. Es posible, también, que un corpus más amplio, seleccionado con otros criterios, ponga de manifiesto alguna ruptura o discontinuidad inevitables por el paso de los tiempos y las transformaciones históricas de la sociedad.

Por último, la presentación del marco teórico y conceptual no pretende agotar la investigación en esos conceptos (ni resolver las implicaciones de la práctica con chicos que, como se dijo, es inescindible del tratamiento conceptual). Tanto la literatura infantil, como la relación entre literatura y práctica filosófica, y la infancia misma son objeto intensivo de investigaciones en la actualidad. El desarrollo dedicado a ellas es expresión de un trabajo en proceso que espera proyectarse y enriquecerse en trabajos futuros.

\section{REFERENCIAS}

AGAMBEN, G. (2015) Infancia e historia. Buenos Aires: Adriana Hidalgo Editora.

ANDRUETTO, M.T. (2012) Sobre el acceso al exceso. Clase 23. Diplomatura Superior en Lectura, Escritura y Educación. FLACSO Virtual Argentina. Recuperado el 23 de julio de 2017, de http://virtual.flacso.org.ar/course/view.php?id=1135

ARENDT, H. (2016a) La crisis en la educación. Entre el pasado y el futuro. Ocho ejercicios sobre la reflexión política. Barcelona: Ariel.

ARENDT, H. (2016b) ¿Qué es la libertad? Entre el pasado y el futuro. Ocho ejercicios sobre la reflexión política. Barcelona: Ariel.

ARPES, M. y RICAUD, N. (1997) "Estrategias de ruptura en textos de literatura infantil". Revista Espacios No 8.

ARPES, M. y RICAUD, N. (1998) "Sentidos enmascarados. Parodia y ruptura en la emergencia de una literatura para niños en la Argentina". Revista Semiosfera. Humanidades/Tecnologías, No 9, Otoño 1998, Universidad Carlos III de Madrid.

ARPES, M. y RICAUD, N. (2008) Literatura infantil argentina. Infancia, política y mercado en la constitución de un género masivo. Bs As, La Crujía.

ARPES, M. (2011) "Territorio coercitivo". Cultura Lij. Reflexiones sobre la literatura infantil y su cultura, Año 2, No 10, marzo/abril 2011, pp.30-35.

BAHAMONDE, S. y ALTAMIRANO, T. (2016) Nuevos materiales literarios: modos de lectura que potencial la reflexión. Encuentros de lo posible y lo imposible: Actas del I Congreso Latinoamericano de Filosofías e Infancias, Julio Fernando Acosta Muñoz et al., eds. Ciudad Autónoma de Buenos Aires: Grupo El Pensadero. Libro digital. 
BIESTA, G. (2017) El bello riesgo de educar. Madrid: Ediciones SM.

CABRERA DELGADO, L. (2014) El absurdo fantástico en la literatura infantil en Argentina. Miradas y voces de la LIJ. Recuperado el 10 de abril de 2019, de https://miradasyvoces.wordpress.com/2014/09/23/el-absurdo-fantastico-en-la-literatura-

infantil-en-argentina/

CARLI, S. (2009) La cuestión de la infancia: Entre la escuela, la calle y el shopping. Bs As: Paidós.

COLOMER, T. (2010) Introducción a la literatura Infantil y juvenil actual. Madrid: Síntesis. DEVETACH, L. (2008) La construcción del camino lector. Córdoba. Comunicarte.

DOMINGUEZ, P. (Ed.) (2017) Diálogos entre mediadores de lectura. Algunas reflexiones sobre literatura infantil y juvenil. C. Rivadavia: EDUPA.

GUDELEVICIUS, M. (2008) Educación y dictadura. Las primeras medidas en materia educativa del Proceso de Reorganización Nacional: análisis de la gestión Guzzetti. V Jornadas de Sociología de la UNLP, 10, 11 y 12 de diciembre de 2008, La Plata, Argentina. Actas. La Plata: UNLP. FAHCE. Departamento de Sociología. Recuperado el 15 de noviembre de 2018, de http://www.memoria.fahce.unlp.edu.ar/trab_eventos/ev.6122/ev.6122.pdf

HAYNES, J. y MURRIS, K. (2012) Picture books. Pedagogy and Philosophy. New York: Routledge.

IVERNIZZI, H. y GROCIOL, J. (2002) Un golpe a los libros: represión a la cultura durante la última dictadura militar. Buenos Aires: Eudeba.

KOHAN, W. (2004). Infancia entre educación y filosofía. Barcelona. Laertes.

MACHADO, A.M. y MONTES, G. (2003) Literatura infantil. Creación, censura y Resistencia. Buenos Aires: Sudamericana.

MEDINA, M. y PAC, A. (2016) Un filósofo en el monte chaqueño. Don Sapo, personaje de Gustavo Roldán. Encuentros de lo posible y lo imposible: Actas del I Congreso Latinoamericano de Filosofías e Infancias, Julio Fernando Acosta Muñoz et al., eds. Ciudad Autónoma de Buenos Aires: Grupo El Pensadero. (109-116). Libro digital.

MONTES, G. (1990) El corral de la infancia. Acerca de los grandes, los chicos y las palabras. Buenos Aires: Libros del Quirquincho.

MONTES, G. (2006) La gran ocasión. Buenos Aires: Min. de Educación, Ciencia y Tecnología de la Nación.

NARODOVSKI, M. (2004) El desorden de la educación. Ordenado alfabéticamente. Buenos Aires: Prometeo.

MORAN, M. (2009). Fantasía bajo sospecha: Censura, lectura y libertad en algunos libros infantiles prohibidos durante el Golpe de Estado (1976-1983) en Argentina. I Jornadas de Poéticas de la Literatura Argentina para Niñ@s, 23 de octubre de 2009, La Plata, Argentina. EN: Actas. La Plata: . Consultado el 15 de noviembre de 2018,en: http://www.memoria.fahce.unlp.edu.ar/trab_eventos/ev.7734/ev.7734.pdf

ORIGGI, A. (2014) Aspectos polifónicos en el discurso del disparate en la obra de María Elena Walsh. Miradas y Voces de la LIJ. Recuperado el 10 de abril de 2019, de https://miradasyvoces.wordpress.com/2014/07/25/aspectos-polifonicos-en-el-discurso-del-

disparate-en-la-obra-de-maria-elena-walsh/

PAC, A. (2018) Filosofía con niños y Literatura: una alianza potente para la reflexión. García, F., Duthie, E., Robles, R. (Eds.). Parecidos de familia. Propuestas actuales en Filosofía para Niños / Family ressemblances. Current proposals in Philosophy for Children. Madrid: Anaya, 214-225.

PAC, A. y BAHAMONDE, S. (2017) La reflexión filosófica y la literatura infantil 'políticamente incorrecta': ¿un desafío?; ¿para quién? Diálogos entre mediadores de lectura (Domínguez, P, comp.). Comodoro Rivadavia: Editorial Universitaria de la Patagonia EDUPA. 
PAC, A. y BAHAMONDE, S., ALONSO, J., ALTAMIRANO, T., MEDINA, M., RAMON, M. (2017). Cuentos de amor: tradición y ruptura en la literatura infantil. Revista Hermeneutic $N^{\circ} 15$ - 2016/2017. Consultado el 23 de junio de 2019 en, http://publicaciones.unpa.edu.ar.

PETIT, M. (2016) Leer el mundo. Experiencias actuales de transmisión cultural. Buenos Aires: FCE.

PESCLEVI, G. (2014) Libros que muerden: literatura infantil y juvenil censurada durante la última dictadura cívico-militar. Buenos Aires: Biblioteca Nacional.

RANCIERE, J. (2009) El reparto de lo sensible. Estética y política. Santiago: LOM Ediciones.

RAMON, M. (2016) Entrecruzamiento entre Filosofía y Literatura con niños: la Perspectiva Psicopedagógica. Encuentros de lo posible y lo imposible: Actas del I Congreso Latinoamericano de Filosofías e Infancias, Julio Fernando Acosta Muñoz et al., eds. Ciudad Autónoma de Buenos Aires: Grupo El Pensadero. Libro digital.

ROLDAN, G. (2011) Para encontrar un tigre. La aventura de leer. Córdoba: Comunicarte. SPLITTER, L., SHARP, A. (1995) Teaching for Better Thinking. The Classroom Community of Inquiry. Melbourne: ACER.

TURIN, J. (2014) Los grandes libros para los más pequeños. Buenos Aires: FCE.

\section{Corpus}

BELGRANO, M. (1977) Recuperado el 25 de octubre de 2019, de https://ilustracion.fadu.uba.ar/2015/11/08/los-zapatos-voladores-1977-sara-conti-centroeditor-de-america-latina/

BORNEMANN, E. (2003) Un elefante ocupa mucho espacio. Buenos Aires: Alfaguara. DEVETACH, L. (2006) La torre de cubos. Buenos Aires: Colihue.

\section{Documentos}

Dirección General de Cultura y Educación de la Provincia de buenos Aires. Consultado el 14 de mayo de 2019, en http://servicios.abc.gov.ar/lainstitucion/sistemaeducativo/educacioninicial/destacado24marzo/ reflexion_el\%20pueblo_\%20que_\%20no_\%20queria_ser_\%20gris.pdf

Ministerio de Cultura y Educación de la Nación Argentina (1977) Subversión en el ámbito educativo (Conozcamos a nuestro enemigo). Buenos Aires. Consultado el 4 de mayo de 2019, en http://www.bnm.me.gov.ar/giga1/documentos/EL003637.pdf

P.E.N. DECRETO 3155/1977. Consultado el 4 de mayo, en http://www.bnm.me.gov.ar/giga1/normas/4853.pdf

\section{Páginas web}

PLAN NACIONAL DE LECTURA, planlectura.educ.ar

IMAGINARIA-Revista Quincenal Sobre Literatura Infantil y Juvenil,

Www.imaginaria.com.ar

CUADERNOS DE LITERATURA INFANTIL Y JUVENIL, www.revistaclij.com 


\section{ANEXO I \\ LISTADO DE LIBROS CENSURADOS}

Fuente: PESCLEVI, G. (2014) Libros que muerden: literatura infantil y juvenil censurada durante la última dictadura cívico-militar. Buenos Aires: Biblioteca Nacional.

\section{Álvaro Yunque}

Nuestros muchachos, Editorial Plus Ultra, Colección Juvenil, Buenos Aires, 1975

El amor sigue siendo niño, Ed. Plus Ultra, Colección Juvenil $2^{\circ}$ edición, Buenos Aires, 1974

Niños de hoy, Editorial Plus Ultra, Colección Juvenil, 1975

\section{José Murillo}

Mi amigo el pespir, Editorial Guadalupe, 1977

Renancó y los últimos huemules, 1975

\section{Javier Villafañe}

Don Juan el zorro (previa censura Onganía), 1963

\section{Francisco Espínola}

Saltoncito, 1971

\section{Enrique Medina}

Pelusa rumbo al sol, 1976

\section{Arkadi Petróvich Gaidar}

Obras escogidas, 1974

La tacita azul, 1974

\section{Laura Devetach}

La torre de cubos, 1973

Elsa Bornemann

Un elefante ocupa mucho espacio, 1975

Jacques Prévert

Cuentos para chicos traviesos, 1974

Antoine de Saint-Exupéry

El principito, 1951

\section{Agnés Rosenstiehl}

El nacimiento, los niños y el amor, 1976. 


\section{Beatriz Doumerc y Ayax Barnes}

Cómo se hacen los niños, 1974

El pueblo que no quería ser gris, 1975

La línea, 1975

\section{Mario Lodi}

La ultrabomba

\section{Augusto Bianco}

Chile no es un cuento

El cuento de la publicidad

\section{Graciela Cabal y Martha Greiner}

Jacinto, 1977

\section{Margarita Belgrano}

Los zapatos voladores, 1976

El salón vacío, 1978

\section{María Elena Walsh}

Aire libre, 1967

Mirta Goldberg

Viento en popa, 1979

Cuentos de Polidoro

Editorial Schapire

Ediciones Fausto

Editorial Aymi

Ediciones Rompan Fila

Ediciones de la Flor

Centro Editor de América Latina

Los cuentos de Chiribitril

Nueva Enciclopedia del Mundo Jóven

Editorial Jorge Álvarez

Editorial Argentina Arístides Quillet 
Editorial La Pléyade

Editorial Granica

Ediciones Junior 


\section{ANEXO II \\ LISTADOS RECOMENDADOS POR EL PLAN LECTOR}

(se resaltan los textos prohibidos)

Fuente: Plan Nacional de Lectura, planlectura.educ.ar

\begin{abstract}
Colección Presentes, Francisco "Paco"

Oroundo

Ad Astra, Conti Aroldo

Sudeste, Fragmento,

Conti Aroldo

Crecer en poesía, Qué bien se vuela soñando, inicial y primer ciclo

Ellas llevan la vida en el pelo, Eduardo Galeano

Colección Narrativas, Ciencia y ficción

Colección Narrativas, Historia y ficción

Cuentos de Polidoro, Mitos y cuentos tradicionales
\end{abstract} primaria

Crecer en poesía, Piedra libre, inicial $\mathrm{y}$ primer ciclo primaria

Crecer en poesía, No sabés cuanto te quiero, segundo ciclo primaria

Crecer en poesía, Me han dicho que has dicho un dicho, inicial y primer ciclo primaria

Crecer en poesía, Espejos en el suelo, segundo ciclo primaria

Crecer en poesía, Cegado de luna, segundo ciclo primaria

Crecer en poesía, A que altura empieza el cielo, segundo ciclo primaria

La ruta del sol hacia las Indias, Eduardo Galeano

Verderías, Eduardo Galeano
Cuentos de Polidoro, Más y más cuentos

Cuentos de Polidoro, Los clásicos

Cuentos de Polidoro, Historias de América

Cuentos de Polidoro, Aventuras de Don Quijote

Mafalda y sus amigos

Mafalda y la familia

Mafalda y la escuela

Mafalda y el mundo

Un tal Lucas, fragmentos, Julio Cortázar

Historias de cronopios y famas, fragmentos, Julio Cortázar

Graffiti en Queremos tanto a Glenda, Julio Cortázar

Casta tomada, en Bestiario, Julio Cortázar
Axolotl, en Final de juego, Julio Cortázar

Colección Con nuestra voz, Estamos

Colección Con nuestra voz, Cantamos

Colección Con nuestra voz, Enseñamos

Colección Con nuestra voz, Recordamos

Colección Con nuestra voz, Creamos

Colección Presentes, Roberto Santoro

Colección Presentes, Héctor Germán

Oesterheld

Colección Presentes, Haroldo Conti

Ovillo de trazos.

Ovillo de trazos

¿Vampiros en Valaquia?, Agustín Adúriz-Bravo

¿Que viva el coyote!, Eduardo Wolovelskye

\section{Cuba, José Martí}

Vivir en el campo no cambiará las cosas y El hormiguero, Sergio Aguirre

Velorio con torta, Iris Rivera 
Una vuelta por el Chaco húmedo, Omar Lobos

Una tarde en el monte chaqueño, Oche Califa

Una primavera muy particular, Margarita Eggers Lan

Una conversación mojada, Oche Califa

Un elefante ocupa mucho espacio, Elsa Bornemann

Un e-mail para la abuela, María Inés Falconi

Un animal sabedor, Oche Califa

Último hombre, Mito y realidad del 2 a 0 y Oración con proyecto de paraíso, Eduardo Sacheri

Tras las huellas del dragón, Omar Lobos

Trabalenguas y adivinanzas, recopilación de Carlos Silveyra.

Trabalenguas y adivinanzas, recopilación de Carlos Silveyra

Toda la piel de América, Armando Tejada Gómez

Tito nunca más, Mempo Giardinelli

Tantanakuy Encuentro

Taki Ongoy, Víctor Heredia

Solo de noche, Paloma Fabrykant, Fiestita con animación y Todos los no, Ana María Shua
Señora de los mares, Olga Drennen

Rulos y El jardín del abuelo, Margarita Mainé

Rugido Guazú, Oche Califa

Rosa, María Rosa Lojo

Romance para títeres de los días de mayo

René Morsa, El poeta y la polilla del saco azul, Franco Vaccarini

Reina Mala, Patricia Suárez

Rafles, Luis María Pescetti

Poemas de Alejandra Pizarnik, Olga Orozco y Alfonsina Storni

Humor, Crist

Pobrechico, Esteban Valentino

Pisa pisuela color de ciruela, Poesía de tradición oral

Piel de Judas, Juan José Panno

Piedras como estrellas, Angélica Gorodischer

Perdido, Haroldo Conti

Penélope, Margarita Eggers Lan

Patita, Javier Villafañe

Palabras escritas para vos

No hay tumbas para la verdad, Graciela Bialet
No dejes que una bomba dañe el clavel de la bandeja, Esteban Valentino

Navidad blanca y Así en el cielo como en la tierra, Sandra Comino

Nadar de pie, Sandra Comino

Mujer en consulta y otros microrrelatos, Reina Roffé

Muero contento, Martín Kohan

Monstruo capilar, Fisicoculturísimo, Muchoneta y Magia de regalo, Pablo Bernasconi

Cuentos para los más chicos, Oche Califa y Margarita Eggers Lan

Mil grullas, Elsa Bornemann

Venezuela, Simón Bolívar

Mercosur Rembiasakue, Crist

Memoria en palabras

Maru, la distraída, Margarita Eggers Lan

Mamá, ¿por qué nadie es como nosotros?, Luis María Pescetti

Más linda que nunca, Norma Huidobro

Luces y sombras, Orlando Van Bredam

Los zapaticos de Rosa (fragmento), José Martí 
Los nombres del cielo, Horacio Tignanelli

Los espíritus del Paraná, Darío Lobos

Los cuatro incríbles, Ricardo Mariño

Libertad, ¿Libertad?, ¡Libertad!, Rudy

Los anuncios, La historia de una hormiga, Largo llorar y El grillo, María Cristina Ramos

Lila y las luces, Sylvia Iparraguirre

Las figuritas de Federico, Guillermo Saccomano

Las buenas y las malas del Aguará Guazú, Oche Califa

La vuelta al mundo, Javier Villafañe

La visita, Oche Califa

La vida de Aca'í y Carayá, El primer fuego, Leyendas, Feliciano Acosta Alcaraz

La sirena y el capitán, María Elena Walsh

La niña tortugra, Jorge Accame

La mirada del lince, Diego Hurtado De Mendoza

La marca del ganado, Pablo De Santis

La luz de mis ojos, Darío Lobos
La leyenda del viento,

Oche Califa

La inspiración, Valdivieso y Último piso, Pablo De Santis

La guitarra y el cantor, No me dejes partir viejo algarrobo, Malambo, Romance de la vidalita riojana, Mi huella, Quebrachito blanco, El río, Zamba y El vendedor de yuyos, Atahualpa Yupanqui.

La gloria de ser difícil y Banderín solferino, Juan Sasturain

La casa gris, Canela

La canoa de cuero, Silvia Schujer

La biblioteca de Don Leopoldo, Graciela Perrone 